\title{
Efficacy and Safety of the Combination of Ropivacaine, Bupivacaine and Fentanyl in Spinal Anesthesia
}

\author{
MD Legnini Pappalardo Luciana*, MD Estrada Estrada Sara H, MD Reynoso Pérez Norma A, and MD \\ Jaime A Ramírez Villagómez
}

Department of Anesthesiology of Guadalajara's Civil Hospital “Fray Antonio Alcalde” University of Guadalajara, México

Submission: February 17, 2020; Published: February 24, 2020

*Corresponding author: MD Legnini Pappalardo Luciana, Department of Anesthesiology of Guadalajara's Civil Hospital "Fray Antonio alcalde" University of Guadalajara, Jalisco, México

Summary

Objective: The aim of this study is to compare clinical parameters observed in spinal anesthesia, using the combination of hyperbaric bupivacaine with isobaric ropivacaine and fentanyl (BRF), versus hyperbaric bupivacaine with fentanyl (BFS), in procedures scheduled for surgery under neuraxial block.

Methods: This was a prospective, randomized, double blind. We included 28 patients scheduled for surgery, 14 per group, with a level of significance of $5 \%(=0.05)$ and a statistical power of $80 \%$, randomly distributed, without contraindications for the application of neuraxial block. ASA I-III, older than 18 years. Neuraxial block and local anesthetic solution were applied in the subarachnoid space. Block latency, vital signs, initial and final sensory level, initial and final motor level, hemodynamic changes, presence of pain, adverse reactions and patient comfort were evaluated.

Results: A similar level of motor block was observed but a greater sensory block when RBF was administered. The total time of duration was almost double for the BRF group. In both groups hemodynamic stability was observed without vasoactive drug requirements. In the RBF group a decrease in blood pressure was observed 20 minutes after the application of the block, instead in the BFS group the decrease in blood pressure occurred in the first minutes. The duration of analgesia was similar for both groups. No statistically significant difference was found regarding the presentation of adverse effects in the first 24 hours after surgery.

Conclusions: Using the combination of BRF, a potentiation synergy occurs, with the same efficacy and safety as BFS, but also with the advantage of a longer duration of motor and sensory block.

\section{Introduction}

The Spinal block is the introduction of a local anesthetic into the subarachnoid space, with the consequent interruption in the transmission of the action potentials, and nerve block [1]. It's been reported this anesthetic technique reduce cardiovascular and pulmonary morbidity and mortality, reducing also the response to stress, and the incidence of postoperative nausea and vomiting, with the benefit of rapid improvement, and early hospital discharges [2]. Despite the multiple benefits of neuraxial techniques, sometimes the duration of sensitive block is insufficient to be able to complete the surgical procedure successfully, requiring the administration of multiple doses by peridural catheters, or even deep sedation. On the other hand, the current local anesthetics do not have all the properties to be considered as an ideal drug: a rapid onset of action, a long duration of the sensory block, and a short duration of the motor block, with limited toxic effects. That the reason we have studied the combination of anesthetic agents to obtain additive benefits of both drugs, using a single low dose that reduces the toxicity caused by higher doses of a single anesthetic. These combinations of different local anesthetics have been reported mainly to be used in the epidural space $[3,4]$. Bupivacaine is a local anesthetic belonging to the amino-amide class that, when introduced into the intrathecal space, the onset of sensory blockage is very fast (in one minute), obtaining maximum motor and sensory blockage at 15 minutes. The duration of the sensory block is 2 hours and the motor block are 3 hours [5]. Ropivacaine is a local anesthetic member of the amino-amide class; it was released in the American market for clinical use in 1996, and recently approved by the Food and Drug Administration for use in the subarachnoid space [6]. It is presented as an isobaric solution with a slow onset of action and 
a prolonged duration. The structural difference with bupivacaine makes it less lipid soluble (giving a lower intensity motor block). In addition, it has lower cardiotoxicity and greater differentiation of the motor-sensitive block. When administered in subarachnoid space it has a latency of 5 to 10 minutes and duration of 2 to 3 hours and with postoperative analgesia of up to 9 hours compared to 5 hours provided by bupivacaine and levobupivacaine [7]. It has been shown in the literature that Ropivacaine has additive effects when combined with other amide-type local anesthetics [8], and it is known that concomitant administration of epidural ropivacaine may even prolong the effect of intrathecal bupivacaine [5], on the other hand we have not found any study about the combination of local anesthetics for using in the subdural space. That is the reason we propose the combination of Ropivacaine, Bupivacaine and fentanyl (one of the most used opioids to get analgesia after intrathecal administration) [9]; they have additive effects when applied together in the subarachnoid space, with greater quality and anesthetic depth, trans-surgical safety, and also longer-lasting post-surgical analgesia, which is clinically significant.

\section{Materials and Methods}

We carried out this study in Guadalajara's Civil Hospital "Fray Antonio Alcalde", México. Our study was a controlled, simple randomized, double-blind, clinical trial, conducted within a period of one year, from November 2017 to November 2018.

Physicochemical analysis: A portable densitometer Anton Paar DMA 35 was used, which uses oscillating U-tube technology to measure the density values of a sample. To determine the baricity and predict the dispersion of local anesthetics, this measurement was made at 37-38 Celcius degrees [10]. (Table 1). We also used a manual pH-meter (BECKMAN PH METER) with automatic buffer recognition. The customized liquid crystal display simultaneously shows the $\mathrm{pH}$ readings with temperature compensation and manually set temperature. Two $\mathrm{pH}$ determinations of the mixture of local anesthetics (with and without opioid) were made at room temperature (26 Celsius degrees in the laboratory) and at $37^{\circ} \mathrm{C}$. (Table 2)

Table 1: Density of Local Anesthetics and mixed.

\begin{tabular}{|c|c|}
\hline Local anesthetics & Density \\
\hline Bupivacaine & 1,031 \\
\hline Ropivacaine & 1,005 \\
\hline Fentanyl & $0,998-0,996$ \\
\hline Ropivacaine/Bupivacaine & 1,015 \\
\hline Ropivacaine/Bupivacaine/Fentanyl & 1,012 \\
\hline
\end{tabular}

Table 2: $\mathrm{pH}$ of local anesthetics mixtures.

\begin{tabular}{|c|c|c|}
\hline $\mathbf{p H}$ of Local Anesthetics Mixtures & $\mathbf{2 6}^{\circ} \mathbf{C}$ & $\mathbf{3 7}^{\circ} \mathbf{C}$ \\
\hline Bupivacaine/ropivacaine & 4,71 & 5,10 \\
\hline Bupivacaine/ropivacaine/fentanyl & 4,96 & 5,18 \\
\hline
\end{tabular}

Sample calculation: A P1 $=0.023$ is obtained based on the article by Jagtap S. Cols [11]; a significance level of 5\% (= 0.05) and a statistical power of $80 \%$ are established, with a sample adjusted to $20 \%$ losses: 2.4 , thus obtaining 14 patients per group.

Anesthetic procedure: Prior authorization from the Ethics and Research Committee of the Guadalajara Civil Hospital Fray Antonio Alcalde (Reg. 132/14.) Informed consent was obtained from 28 patients, older than 18 years, with an American Society of Anesthesiologist's physical status I-III. Scheduled to surgery, and candidates for the application of neuraxial block. The exclusion criteria were patient refusal, contraindications for the application of neuraxial block, deterioration of cardiovascular, pulmonary, renal or hepatic function. Once included in the study, they were distributed randomly by choosing a sealed envelope (simple randomization) in one of the following groups:

a) BRF Group: $15 \mathrm{mg}$ of $0.75 \%$ hyperbaric bupivacaine $(2 \mathrm{ml})+15 \mathrm{mg}$ of $0.75 \%$ ropivacaine $(2 \mathrm{ml})+25 \mathrm{mcg}$ of fentanyl

b) BFS Group: $15 \mathrm{mg}$ of $0.75 \%$ hyperbaric bupivacaine $(2 \mathrm{ml})+2 \mathrm{ml}$ of $0.9 \%$ saline solution $+25 \mathrm{mcg}$ of fentanyl.

Both the patient and the medical researcher were unaware of the assignment to each group (double blind); The medication mixture was prepared by a third researcher, who had no intervention during the surgical procedure. Once at the operation room, non-invasive monitoring was performed. For anxiolysis we administered with midazolam $(0.03 \mathrm{mg} / \mathrm{kg})$. In a sitting position, with aseptic technique, subarachnoid space was located at the level of L1-L2 with Whitacre 27 needle, and the $4.5 \mathrm{ml}$ of local anesthetic solution was administered. We inserted an inert epidural catheter in a cephalic position just in case for additional doses were required. The patient was placed in dorsal decubitus position, with an angle of $20^{\circ}$ of trendelemburg for 5 minutes, oxygen was administered at $3 \mathrm{l} / \mathrm{min}$, with nasal tips. Vital signs (oxygen saturation, blood pressure, electrocardiogram, oxygenation, body temperature), initial sensory level (picket and swab), initial motor level (Modified Bromage scale) were recorded. Vital signs were recorded every 5 minutes during the entire surgery, also the use of vasoactive drugs or atropine, the presence of pain, nausea, vomiting and other adverse reactions. Given a prolongation of the surgical event or an insufficient level of blockage, we administered $2 \%$ lidocaine by peridural catheter, in a sufficient dose to reach the requirements of the patient and surgery. Intravenous analgesia was administered with acetaminophen $1 \mathrm{gr}$, and dexketoprofen $50 \mathrm{mg}$.

Post-anesthetic evaluation: Once the surgical procedure was finished, we verified the final sensory level, final motor level, presence of pain (analogous visual scale), and the peridural catheter was removed. In the hospitalization room, we evaluated the patient's post-surgical comfort using a satisfaction form, validated for this purpose [12]. During the first 24 hours after surgery, we assessed the presence of pain, nausea, vomiting, constipation, and urination alterations through the use of a mobile app for Andriod operating system. The stable version of the application maintained an asynchronous connection with the 
server, which automatically stored the data entered by the user in a non-relational database. (Figure 1)

¿Tuvo náuseas?
$\square$ Durante la operación
$\square$ Sin náuseas
$\square$ En recuperación
$\square$ A las 8 hs
$\square$ A las 12 hs
$\square$ A las 24 hs
Figure 1: Example from the App used in the assessment.

Statistical analysis: We used the Statistical Package for the Social Sciences version 21 [13] for statistical analysis. Any value of $\mathrm{p}<0.05$ is considered statistically significant.

\section{Results}

We included a total of 28 patients (14 per group) in this study. Of these, 26 were female and 2 males, between 23 and 72 years. When analyzing the Levene test of equality of variances, and the t-test of equality of means for the independent samples (RBF and BFS groups), no statistically significant difference was found for the variables: sex, age, weight, height and ASA's physical status. The surgeries performed were: Body contour (21.43\%), colpocleisis (10.71\%), abdominal hysterectomy (10.71\%), vaginal hysterectomy (7.14\%), knee arthroscopy (7.14\%), others (42.87\%). The latency for the BFS group was $5.86 \pm 1.58$ minutes, with a total anesthetic time of $1.58 \pm 0.96$. Only two patients required activation of the peridural catheter (14.2\%). In the BRF group, the mean for latency was $7.07 \pm 2.36$ minutes ( $p$ 0.265); with an anesthetic time of $2.66 \pm 1.36$ (p: 0.258 ). Similarly, two patients required use of the epidural catheter (14.2\%). The initial sensory level reached in both groups was from T2 to T6. The final sensory level was found in a higher percentage in T4-T5 levels (57.2\% for both groups). Although the final sensory levels observed in the BRF group were higher, there was no statistically significant difference. ( $p=0.494)$. The initial grade of blockade according to the Bromage's scale was mostly 3 in both groups (BFS 85.7\%, BRF 92.9\%, $p=0.341$ ). Regarding the final level according to Bromage's scale, it was observed a higher percentage $(85.7 \%)$ of patients in the BRF group remained with Bromage's grade of 3 at the end of the surgery, compared with the BFS group Bromage's grade 3 were only $50 \%$ of patients $(p=0.076)$. (Table 3 )
Table 3: Grade of blockade according to the Bromage's scale.

\begin{tabular}{|c|c|c|c|c|}
\hline \multirow{2}{*}{} & \multicolumn{2}{|c|}{ Initial Bromage's Grade } & \multicolumn{2}{c|}{ Final Bromage's Grade } \\
\cline { 2 - 5 } & BFS & BRF & BFS & BRF \\
\hline 1 & 0 & 0 & 14,3 & 14,3 \\
\hline 2 & 14,2 & 7,1 & 35,7 & 0 \\
\hline 3 & 85,7 & 92,9 & 50 & 85.7 \\
\hline Total & 100 & 100 & 100 & 100 \\
\hline
\end{tabular}

Abbreviations: BFS: Bupivacaine+Fentanyl+Saline solution; BRF: Bupivacaine+Ropivacaine+Fentanyl

The trends on the hemodynamic variables of systolic, diastolic and mean arterial pressure remained stable in the trans operative period with maximum values of $169 \pm 17.92,105 \pm 10.91$, $130 \pm 17.19$ and minimum of $71 \pm 16.18,18 \pm 11.79,38 \pm 16.16$ respectively. No statistical significance was observed in both groups. Ephedrine requirements were $18.92 \pm 13.75$ (maximum 50 $\mathrm{mg}$ ) for the BRF group, and $7.5 \pm 8.02$ for the BFS group (maximum $30 \mathrm{mg}$ ) ( $p=0.08)$. The average maximum heart rate of the BFS group was $119 \pm 15.10$ and the minimum $48 \pm 36.11$ and in the RBF group it was $100 \pm 11.82$ and the minimum $49 \pm 11.25$.9, without statistical significance in both groups (Table 4). Only one patient of the BFS group required administration of Atropine (10mcg/ $\mathrm{Kg}$ ), due to a decrease in heart rate of more than $20 \%$ from the baseline, resolved without major complications $(p=0.309)$. Although the duration of the motor block was not statistically significant $(\mathrm{p}=0.12)$, a notable difference was observed between both groups, with an average duration of 2.17 hours for the BFS group and 4.3 hours for the BRF group (Table 5). Regarding adverse effects, 2 patients of the BFS group presented nausea $(14.28 \%)$ and one patient of the BRF group (7.14\%). One patient from BFS group presented postoperative vomiting (7.14), while two patients in the BRF group (14.28\%). Two patients in the RBF group had evacuation problems. No urinary retention was observed in any patient of the study. About postoperative pain we found the following data using the Visual Analog Scale (VAS), 13 patients of the BFS group (92.9\%) presented mild pain (VAS 0 -2) in UCPA, while only one patient (7.1\%) presented severe pain (VAS 8). Similarly, 13 patients in the RBF group presented mild pain, severe pain appearing in 1 case (VAS 10) ( $p=0.498)$. At 8 hours, 12 patients of the BFS group reported mild pain $(85.7 \%)$, while 2 patients (14.3\%) had moderate pain. Similarly, in the BRF group, 12 patients reported mild pain, while only two patients presented moderate pain $(\mathrm{p}=0.070)$. At 12 hours afther spinal block, 7 patients (50\%) had mild pain In the BFS group, 6 (42.8\%) moderate pain (3-5 VAS) and 1 had severe pain, classified as VAS $10(7.1 \%)$. In the BRF group, 10 patients presented mild pain (71.5\%) while 4 (28.5) reported moderate pain (VAS 4-6) ( $\mathrm{p}=$ 0.679 ). At 24 hours, $100 \%$ of patients in the BFS group reported mild pain, while in the BRF group one patient reported VAS 4 (7.1\%); in the rest of the patients the VAS was less than 2 (92.9\%) $(p=0.574)$. Because the combination used in this protocol has not 
been studied before, we applied a satisfaction questionnaire using the Likert scale, to establish the confort for the patients obtaining for the BFS group $21.4 \%$ of the patients were satisfied, and $78.6 \%$ very satisfied, about the BRF group, $85.7 \%$ were very satisfied and

$14.3 \%$ satisfied. (Table 6)

Table 4: Hemodynamic variables of systolic, diastolic and mean arterial pressure.

\begin{tabular}{|c|c|c|c|c|c|c|c|c|c|}
\hline & \multicolumn{3}{|c|}{ Systolic } & \multicolumn{3}{|c|}{ Diastolic } & \multicolumn{3}{|c|}{ Mean } \\
\hline Blood & BFS & $\mathrm{BRF}$ & $\begin{array}{c}\mathrm{p} \\
\text { (CI:95\%) }\end{array}$ & BFS & $\mathrm{BRF}$ & $\begin{array}{c}p \\
\text { (CI:95\%) }\end{array}$ & BFS & BRF & $\begin{array}{c}p \\
(\mathrm{CI}: 95 \%)\end{array}$ \\
\hline Pressure & $\mathrm{ME} \pm \mathrm{SD}$ & $\mathrm{ME} \pm \mathrm{SD}$ & & $\mathrm{ME} \pm \mathrm{SD}$ & $\mathrm{ME} \pm \mathrm{SD}$ & & $\mathrm{ME} \pm \mathrm{SD}$ & $\mathrm{ME} \pm \mathrm{SD}$ & \\
\hline Baseline & $141,21 \pm 18,20$ & $122,5 \pm 12,145$ & 0,122 & $76,21 \pm 10,707$ & $71,86 \pm 11,079$ & 0,593 & $102,93 \pm 18,002$ & $88,43 \pm 13,3$ & 0,593 \\
\hline $3 \mathrm{~min}$ & $126,14 \pm 18,563$ & $111,57 \pm 13,943$ & 0,623 & $67,57 \pm 9,387$ & $61,57 \pm 17,509$ & 0,341 & $88 \pm 13,399$ & $78,21 \pm 17,647$ & 0,341 \\
\hline $5 \mathrm{~min}$ & $122,36 \pm 6,75$ & $111,57 \pm 13,866$ & 0,704 & $67,36 \pm 13,948$ & $60,93 \pm 14,117$ & 0,612 & $88 \pm 14,223$ & $79,57 \pm 13,455$ & 0,612 \\
\hline $10 \mathrm{~min}$ & $110,64 \pm 12,283$ & $113,07 \pm 15,559$ & 0,724 & $55,5 \pm 18,48$ & $61,07 \pm 8,871$ & 0,284 & $79,86 \pm 13,002$ & $81,57 \pm 11,574$ & 0,284 \\
\hline $15 \mathrm{~min}$ & $108,57 \pm 14,02$ & $107 \pm 14,251$ & 0,87 & $58,29 \pm 11,472$ & $56,86 \pm 10,053$ & 0,546 & $77,14 \pm 11,387$ & $75 \pm 12,115$ & 0,546 \\
\hline $30 \mathrm{~min}$ & $102,08 \pm 17,027$ & $104,36 \pm 13,765$ & 0,81 & $60,08 \pm 15,473$ & $53,36 \pm 10,945$ & 0,344 & $72 \pm 11,045$ & $72,29 \pm 11,425$ & 0,344 \\
\hline $45 \mathrm{~min}$ & $110,62 \pm 18,419$ & $99,21 \pm 14,498$ & 0,101 & $59,15 \pm 12,928$ & $52,71 \pm 13,011$ & 0,501 & $77,46 \pm 11,065$ & $71,36 \pm 10,71$ & 0,501 \\
\hline 1 hour & $107,77 \pm 16,629$ & $106,57 \pm 14,955$ & 0,149 & $58 \pm 10,583$ & $51,79 \pm 12,436$ & 0,549 & $76,46 \pm 13,119$ & $70,14 \pm 12,673$ & 0,549 \\
\hline $1,5 \mathrm{~h}$ & $115,7 \pm 13,76$ & $104,09 \pm 8,848$ & 0,386 & $60,4 \pm 7,975$ & $54,91 \pm 6,685$ & 0,379 & $77,5 \pm 7,92$ & $72,18 \pm 6,447$ & 0,379 \\
\hline $2 \mathrm{~h}$ & $100 \pm 26,533$ & $107,27 \pm 9,655$ & 0,368 & $55,4 \pm 16,196$ & $53,27 \pm 9,84$ & 0,582 & $71,6 \pm 17,501$ & $72 \pm 7,5765,007$ & 0,582 \\
\hline $2,5 \mathrm{~h}$ & $107,67 \pm 25,106$ & $114 \pm 14,56$ & 0,338 & $61,33 \pm 16,042$ & $52 \pm 10,354$ & 0,253 & $86 \pm 18,248$ & $75,67 \pm 5,007$ & 0,253 \\
\hline $3 \mathrm{~h}$ & $107 \pm$ & $108,8 \pm 9,985$ & 0,285 & $63 \pm$ & $57,6 \pm 4,775$ & 0,663 & $81 \pm$ & $73,8 \pm 7,463$ & 0,663 \\
\hline $3,5 \mathrm{~h}$ & & $109,25 \pm 24,581$ & & & $54 \pm 11,195$ & & & $74,25 \pm 14,056$ & \\
\hline $4 \mathrm{~h}$ & & $106,5 \pm 27,343$ & & & $56 \pm 10,231$ & & & $73 \pm 13,292$ & \\
\hline $4,5 \mathrm{~h}$ & & $120,5 \pm 14,84924$ & & & $57 \pm 7,07$ & & & $78 \pm 8,48528$ & \\
\hline $5 \mathrm{~h}$ & & 97 & & & $68 \pm$ & & & $80 \pm$ & \\
\hline Final & $110,71 \pm 12,269$ & $107,93 \pm 12,282$ & 0,745 & $58,93 \pm 11,075$ & $58,86 \pm 10,091$ & 0,319 & $66,71 \pm 29,546$ & $68,79 \pm 22,361$ & 0,319 \\
\hline
\end{tabular}

Statistical significance when obtaining $\mathrm{P}<0.05$.

Abbreviations: ME: Mean; SD: Standard deviation, h: hours

Table 5: Motor Block duration.

\begin{tabular}{|c|c|c|}
\hline \multicolumn{3}{|c|}{ Motor block Duration } \\
\hline & BFS & BRF \\
\hline ME+SD & $2,1729 \pm 0,52184$ & $4,3 \pm 1,04366$ \\
\hline Minimum & 1,45 & 2,3 \\
\hline Maximum & 3 & 6 \\
\hline
\end{tabular}

Abbreviations: BFS: Bupivacaine+Fentanyl+Saline solution; BRF Bupivacaine+Ropivacaine+Fentanyl; ME: Mean; SD: Standard deviation

Table 6: Confort for the patients using Likert scale.

\begin{tabular}{|c|c|c|c|c|c|}
\hline & & Satisfied & $\begin{array}{c}\text { Very } \\
\text { satisfied }\end{array}$ & total & $\begin{array}{c}\text { p } \\
\text { (CI:95\%) }\end{array}$ \\
\hline \multirow{2}{*}{$\begin{array}{l}\text { Study } \\
\text { group }\end{array}$} & BRF & 2 & 12 & 14 & 0.622 \\
\cline { 2 - 6 } & BFS & 3 & 11 & 14 & \\
\hline Total & & 5 & 23 & 28 & \\
\hline
\end{tabular}

Abbreviations: BFS: Bupivacaine+Fentanyl+Saline solution; BRF: Bupivacaine+Ropivacaine+Fentanyl; $\mathrm{Cl}$ : Confidence Interval

\section{Discussion}

It is known that concomitant administration of epidural ropivacaine may prolong the effect of intrathecal bupivacaine5, but there are no clinical trials demonstrating this interaction when both local anesthetics are administered in the subarachnoid space. In our study, the efficacy and safety of the combination of ropivacaine, bupivacaine and fentanyl applied in the subarachnoid space as an alternative to a single local anesthetic and an opioid was analyzed and assessed. Reddy, A. C. et al. [14], point out that the onset of sensory blockade was faster with Bupivacaine ( $4 \mathrm{~min})$ compared to ropivacaine (6minutes); This is consistent with what was found in our study, since a similar degree of motor block was observed but a latency for greater sensory block was given when ropivacaine-bupivacaine-fentanyl was administered $(7.07 \pm 2.36 \mathrm{~min})$. In addition, we found the total duration of the motor block was almost double the time for the ropivacaine-bupivacaine-fentanyl group. This fact contrasts with all published studies in which they document that the use of subdural ropivacaine provides significantly shorter motor block duration (McNamee D et al. [15], Cannata, F et al. [16], Layek A et al. [17]). In particular, we believe that this phenomenon so discordant with what was previously published by other authors is due to the fact that neither have two local anesthetics combined in the subarachnoid space and the comparisons have been of both local anesthetics separately. Which leads us to conclude 
that when bupivacaine and ropivacaine are combined in the subarachnoid space, a potentiation synergy of both drugs occurs, with an increase in the duration of the motor block, maintaining hemodynamic stability and respiratory function. As known, one of the secondary effects of local anesthetics is arterial hypotension due to loss of sympathetic tone and bradycardia. The results obtained in our study confirm that despite the administration of a larger total dose of local anesthetics in neuroaxis $115 \mathrm{mg}$ of ropivacaine $+15 \mathrm{mg}$ of bupivacaine), in both groups hemodynamic stability was observed without vasoactive drug requirements; which follows the same line proposed by Jagtap S. et al. [11], who mention that intrathecal ropivacaine-fentanyl provided satisfactory anesthesia with hemodynamic stability; and by Malinovsky J et al. [18] who stablished that intrathecal ropivacaine application provides similar motor and hemodynamic effects but less potent than bupivacaine. Another aspect to mention is the hemodynamic tendencies in both groups; in our study we found that in the ropivacaine-bupivacaine-fentanyl group there was a decrease in blood pressure (predominantly diastolic) 20 minutes after the application of the anesthetic mix, versus the bupivacainefentanyl -saline solution, where the decrease in blood pressure occurred mainly in the first minutes of spinal anesthesia.

According to the study published by Varun S. et al. [19] Intrathecal administration of ropivacaine-fentanyl has a shorter duration of analgesia compared to bupivacaine-fentanyl. In contrast to what was observed in our clinical trial, where the duration of analgesia was similar. Only two patients (one from each group) reported severe pain with the requirement of intravenous opioid rescue. There were no toxic cardiovascular, neurological, or major complications from the combination of local anesthetics, which allows us to propouse that its use is effective and safe. This is supported by Gupta, HB et al. [20], who claim that the use of intrathecal Ropivacaine is safe and effective with minimal side effects. It should also be noted that through the satisfaction questionnaire, almost all patients (85.71\%) reported being very satisfied with the anesthetic technique, and $100 \%$ reported that if they had to have a new intervention they would do so under the same anesthetic conditions. It is important to highlight that it has been demonstrated by laboratory and experimental research (prior to application in healthy voluntary patients), that the combination of ropivacaine-bupivacaine-fentanyl can be classified as hyperbaric with respect to cerebrospinal fluid; This data is essential to predict their clinical behavior, because as reported by Borah, TJ et al. [21], subarachnoid injection of glucose-free isobaric ropivacaine $(0.5 \%$ and $0.75 \%)$ results in a variable dispersion of analgesia. Finally, it should be noted that a weakness of our study was the multiplicity of surgical procedures, because it causes different degrees of aggression to the tissues, which will obviously have an impact on the surgical stress and postoperative evolution of the patients. This allows us to infer that it would be important to carry out further studies with a greater number of patients, and also homogenize the type of procedure.

\section{Conclusion}

With our study we demonstrate that with the combination of ropivacaine, bupivacaine and fentanyl there is a potentiation synergy, which can be applied in the subarachnoid space with the same efficacy and safety as bupivacaine-fentanyl, but also with the advantage of greater duration of motor and sensory block. Therefore, the combination of local anesthetics can be used as an alternative in case of prolonged surgical procedures, with the possibility of applying a single subarachnoid dose, without needing multiple punctures or placement of peridural catheters.

\section{References}

1. Miller RD, Eriksson LI, Fleisher LA, Wiener Kronish JP, Cohen NH, et al. (2014) Miller's anesthesia e-book. Elsevier Health Sciences. 56: 16841721

2. Chatterjee S, Bisui B, Mandal A, Sheet J, Sengupta S, et al. (2014) Effects of intrathecal hyperbaric ropivacaine versus hyperbaric bupivacaine for lower limb orthopedic surgery. Anesth Essays Res 8(3): 349-353.

3. Howell P, Davies W, Wrigley M, Tan P, Morgan B (1990). Comparison of four local extradural anaesthetic solutions for elective caesarean section. BJA: British Journal of Anaesthesia 65(5): 648-653.

4. Yurtlu D, Kaya K (2013) Ropivacaína, Articaína o la Combinación de Ropivacaína y Articaína en la Anestesia Epidural para Cesárea: Estudio Aleatorio, Prospectivo y Doble Ciego. Brazilian Journal of Anesthesiology (Edicion en Espanol), 63(1): 85-91.

5. González M, Calderon N, Metz G, Szwarc M (2013) Anestesia subaracnoidea con ropivacaína hiperbárica versus bupivacaína hiperbárica asociadas a fentanilo para operación cesárea de urgencia. Ensayo clínico controlado con asignación aleatoria. Anestesia Analgesia Reanimación 26(1) : 4.

6. (2017) Drugs: Ropivacaine (Injection)-FDA presicribing information, side effects and uses.

7. Moore D, Bridenbaugh L, Bridenbaugh P, Thompson G, Tucker G (1972) Does compounding of local anesthetic agents increase their toxicity in humans? Anesthesia \& Analgesia 51(4): 579-585.

8. Gutiérrez A, Olivas J Density Behavior of Local Anesthetics in Low Dose. Comparative Study with Ropivacaine vs. Bupivacaine.

9. Mugabure B, Echaniz E, Marín M (2005) Physiology and clinical pharmacology of epidural and intrathecal opioids. Magazine of the Spanish society of Pain 12(1): 33-45.

10. Reyes P (2010) Anesthesiologist. Spinal anesthesia without motor block. "VI National Congress of Anesthesiology of El Salvador".

11. Jagtap S, Chhabra A, Dawoodi S, Jain A Comparison of intrathecal ropivacaine-fentanyl and bupivacaine-fentanyl for major lower limb orthopaedic surgery: A randomised double-blind study. Indian Journal of Anaesthesia 58(4): 442-446

12. Soliva D, Amaro A, Portuondo A (2003) Satisfaction of those operated with a municipal outpatient surgery program. Surgery and Surgeons 71(2): 116-128.

13. (2012) IBM Corp. Released 2012. IBM SPSS Statistics for Windows, Version 21.0. Armonk, NY: IBM Corp.

14. Reddy A, Singh N, Rao P, Ramachandran T, George S, Bhumika N (2013) Randomized double blinded controlled study of ropivacaine versus bupivacaine in combined spinal epidural anesthesia. Anaesth Pain \& Intensive Care 17(2): 158-161. 
15. McNamee D, McClelland A, Scott S, Milligan K, Westman L (2002) Spinal anaesthesia: comparison of plain ropivacaine $5 \mathrm{mg} \mathrm{ml}-1$ with bupivacaine $5 \mathrm{mg} \mathrm{ml}-1$ for major orthopaedic surgery. $\mathrm{Br} \mathrm{J}$ Anaesth 89(5): $702-706$

16. Cannata F, Amicone M, Canneti A, Luzi M, Reale C (2008) Spinalanaesthesia for transurethral prostate resection: Isobaric ropivacaine $0.75 \%$ versus isobaric bupivacaine $0.5 \%$ : 8AP3-3. European Journalof Anaesthesiology (EJA) 25: 112.

17. Layek A, Maitra S, Gozi N, et al. (2015) Comparison between intrathecal isobaric ropivacaine-fentanyl and bupivacaine-fentanyl in elective infraumbilical orthopedic surgery: A randomized controlled study. Journal of Anaesthesiology, Clinical Pharmacology 31(4): 542-546.

18. Malinovsky J, Charles F, Kick O, Lepage J, Malinge M, et al. (2000) Intrathecal anesthesia: ropivacaine versus bupivacaine. Anesthesia \& Analgesia 91(6): 1457-1460
19. Varun S, Srivastava M, Maurya I, Garg R, Dhama V, et al. (2012) A clinical prospective, randomized study to compare intrathecal isobaric bupivacaine fentanyl and isobaric ropivacaine-fentanyl for lower abdominal and lower limb surgeries. Anaesth Pain \& Intensive Care 16(3): 237-242

20.Gupta H, Amilkanthwar S (2017) A prospective, comparative, observational study of quality of spinal anaesthesia with $0.5 \%$ and $0.75 \%$ plain isobaric ropivacaine in lower abdomen and lower limb surgeries. International Journal of Research in Medical Sciences 4(8): 3134-3140.

21. Borah T, Chakrabartty A, Choudhury D (2016) A comparative study of effect of $0.5 \%$ and $0.75 \%$ isobaric ropivacaine in spinal anaesthesia in patients undergoing elective lower limb surgeries. journal of evolution of medical and dental sciences-jemds. 5(30): 1542-1547.

\section{Your next submission with Juniper Publishers} will reach you the below assets

- Quality Editorial service

- Swift Peer Review

- Reprints availability

- E-prints Service

- Manuscript Podcast for convenient understanding

- Global attainment for your research

- Manuscript accessibility in different formats

( Pdf, E-pub, Full Text, Audio)

- Unceasing customer service

Track the below URL for one-step submission https://juniperpublishers.com/online-submission.php 